\title{
INFECTIVE GRANULOMA OF THE GENITALS IN CHILDREN
}

\author{
BY \\ G. H. V. CLARKE, M.A., M.B., B.S., A.R.I.C. \\ Assistant Registrar, Dermatological Department, University College Hospital, London
}

Survey of the literature shows that there is considerable confusion about genital granulomata. Von Haam (1940) classifies them as venereal and non-venereal. Venereal granulomata may be manifestations of syphilis, gonorrhoea, chancroid, lymphogranuloma venereum, or granuloma inguinale. Non-venereal granulomata may be tuberculous, fusospirochaetal, pyogenic, or saprophytic. The last group includes those due to monilia, B. crassus of Lipschütz, trichomonas, and diphtheria.

The following cases occurring in three children living in the same house and using the same bath water presented an interesting problem in diagnosis.

\section{Case Records}

Case 1. M.D., aged 19 months (figs. 1 and 2), had on the right labium majus an abruptly projecting circumscribed oval tumour measuring 1 in. by $\frac{1}{2}$ in., of firm consistency and considerable induration. When this was first seen a crust covered its surface; when the crust was removed a raw red surface was revealed. The outer border was raised and indurated. The lesion did not appear to be at all painful. The tumour had been present for one month, and there had been no previous illness.

FAMIIY HISTORY. The family surroundings were healthy, but in the same house there was another small girl and also a boy aged $2 \frac{1}{2}$ years with similar lesions on the genitals. No rabbits or cows were kept. All the children used the same bath water.

General medical eXamination. The child was well developed, intelligent, and healthy. No abnormalities were found in respiratory, cardiovascular, or central nervous systems, abdomen, or skeleton. The lymphatic glands were not enlarged, but the inguinal glands were small and shotty.

There was some redness and scaling on the forehead and chin. The general health was unaffected.

Special investigations. The Frei, Mantoux, and Wassermann tests and dark-ground examination were all negative. The red cell count was $5,200,000$ per c.mm. of blood and the white cell count 5,800 per c.mm. (Hb 72 per cent., polymorphs 28 per cent., lymphocytes 68 per cent., monocytes 3 per cent., eosinophils 1 per cent.).
Culture from the lesion yielded a scanty growth of micrococci only. Culture from the nearby skin yielded Strep. haemolyticus, Group G, and Staph. aureus. No pathogens were isolated from the vagina.

A radiograph of the chest was normal.

Biopsy. In the diseased portion the epidermis was replaced by a mass of granulation tissue which extended deeply into the corium. The superficial cells of this mass were chiefly polymorphonuclear leucocytes, whereas in the deeper portion there was a dense fibrous-tissue reaction with scattered lymphocytes and occasional clusters of plasma cells.

The blood vessels appeared healthy, and there were numerous dilated capillaries in the granulomatous mass.

Sections stained by Gram's method revealed a moderate number of bacteria, chiefly Gram positive, in the superficial layers.

Giemsa and Leishman staining revealed no Leishman-Donovan bodies.

Case 2. J.V., aged 19 months (fig. 3), had a purplish-red raised circumscribed oval tumour measuring $\frac{3}{3}$ in by $\frac{1}{2}$ in. on the left labium majus, markedly projecting but with very little induration. A crust covered the surface; this, when removed, gave rise to considerable bleeding, and left a small raw area in the centre considerably smaller than the crust. The outer border was very abruptly raised. The lesion did not appear to be at all painful. It had been present for five months.

There had been vomiting and diarrhoea for one week at the age of 17 months. The child lost weight at first on artificial feeding. The birth weight was $6 \mathrm{lb} .13 \mathrm{oz}$.

FAMIIY HISTORY. An uncle had tuberculosis but had never seen the patient. The mother was a widow.

General medical examination. The patient was a rather weakly looking child of normal intelligence. No abnormalities were found in any of the systems. The lymphatic glands were not enlarged but the inguinal glands were small and shotty. There were a very few papules and some slight erythema on both thighs. The general health was unaffected.

Special investigations. The Frei, Mantoux, and Wassermann tests and dark-ground examination were all negative. The sedimentation rate was 


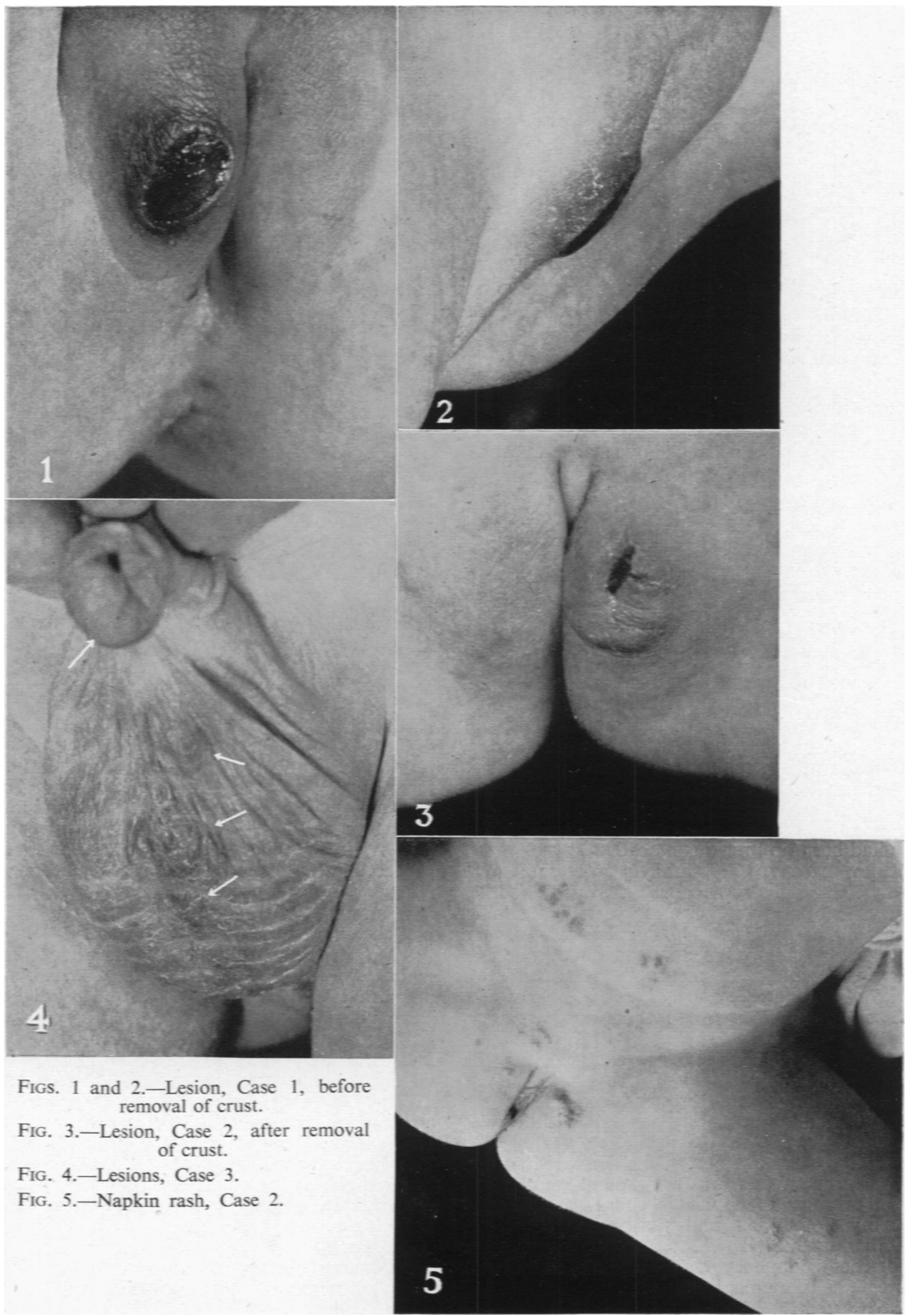

Plate ViI. 
$6 \mathrm{~mm}$. per hour. The white cell count was 8,100 per c.mm. of blood (Hb 70 per cent., polymorphs 29 per cent., lymphocytes 67 per cent., monocytes 3 per cent., eosinophils 1 per cent.).

Culture from the lesion yielded Staph. aureus. Culture from the vagina yielded occasional Gramnegative cocci, Strep. haemolyticus group G, and micrococi.

A radiograph of the chest was normal.

The urine was acid, with a trace of albumin and occasional pus cells. Culture yielded a sparse mixed growth, probably contaminants.

Bropsy. There was simple proliferation of the whole thickness of the epidermis in the diseased area. Beneath this there was a moderate lymphocytic and fibroblastic infiltration in the upper half of the cutis.

Giemsa and Leishman staining revealed no Leishman-Donovan bodies.

Case 3. J.W., aged $2 \frac{1}{2}$ years (fig. 4), on examination was found to have lesions that had almost healed and were considerably smaller than those of the other two children, but some induration was still present. There was one lesion on the prepuce and three on the median raphe of the scrotum. The condition had been present for six months and had been treated by the child's own doctor at a welfare clinic.

FAMIIY HISTORY. The mother had been one year in a mental hospital and was getting a divorce from the father. It was very difficult to persuade her to show her child.

General COndrrion. The child appeared well nourished but backward, and he could not walk or talk.

CULTURE FROM LesYons. - No haemolytic streptococci, Staph. aureus, or C. diphtheria were isolated.

\section{Discussion}

In both girls the lesions clinically bore some resemblance to epitheliomata, but apart from the age of the patients the biopsy findings ruled this out. Against a syphilitic chancre was the long duration (six months in one case) and the negative serological reactions and dark-ground examination. The lesions were clinically unlike tuberculosis, and the chest radiographs and Mantoux tests were negative. Against oriental sore was the fact that the patients had never been abroad (although the fathers had served during the war in the tropics). In any case Leishman-Donovan bodies were not found. Fusospirochaetal lesions are invariably deep ulcers as opposed to granuloma, and moreover they are painful. No organisms of this nature were seen. Against lymphogranuloma venereum were the facts that Frei's test was negative and the inguinal glands completely unaffected. The lack of glandular enlargement, the presence of induration, and the absence of the bacilli ruled out Ducrey's infection.
Again the painlessness, the age of the patients, and the long duration also ruled out the ulcus vulvae acutum of Lipschūtz. Against granuloma inguinale tropicum were the facts that the patients had never been abroad and the circumscribed nature of the lesions. A Bartholin's cyst was a possibility, but no gonococci were found and Bartholin's gland does not develop before puberty. Against diphtheria was the failure to grow this organism, and the facts that both children had been immunized and that diphtheritic lesions are usually painful. Most rare conditions were ruled out by the lack of systemic disturbance.

The only remaining possibility was ecthyma, but against this was the fact that the lesions were solitary and not painful, and confined to the genitals. The medium of infection appeared to have been the bath water and towels. Possibly the fact that Streptococcus haemolyticus group $G$ was present in two of the cases is of significance.

\section{Sequel}

In both girls healing appeared to be initiated by the biopsy and was complete in a few weeks. On discharge the parents were given Ung. hyd. ammon. dil. to apply and were told to report in three weeks. When seen at the conclusion of this period M.D.'s lesion had remained soundly healed, but J.V. had developed a typical napkin rash, or Jacquet's erythema, a strong smell of ammonia being noticed. The classical appearances so well described by Adamson (1909) were present, viz. erythema and multiple ulcerated papules of the pelvis, thighs, and lower abdomen, while the flexures remained free (fig. 5).

\section{Conchusion}

The lesions found seem to have been of the same nature as the ecthymatous lesions of Jacquet's erythema, but what is unique is the fact that they were solitary and so large, so indolent and so extraordinarily similar in the two girls. The common presence of the group $G$ streptococcus lends support to Rosenow's theory of elective localization.

Acknowledgement is due to Dr. I. M. Scott for the report on the biopsies, to Dr. B. E. Schlesinger under whose care the second patient was admitted, and to Dr. W. N. Goldsmith for advice.

\section{REFERENCES}

Adamson, H. G. (1909). Brit. J. Derm. Syph., 21, 37. Haam, E. von (1940). J. Amer. med. Ass., 114, 291.

Jacquet, L. (1900) La Pratique Dermatologique. Masson. Paris.

Rosenow, E. C. (1930). Verhandl. deutsch. Gessellsch. inn. Med. Kong., 42, 408. 